\title{
Towards a UML-based Reference Model for Blended Learning
}

\author{
http://dx.doi.org/10.3991/ijes.v2i3.3818 \\ J. R. Quadros ${ }^{1}$, D. Oliveira ${ }^{2}$, A. Queiroz ${ }^{1}$, E. Ogasawara ${ }^{1}$, C. Schocair ${ }^{1}$ \\ ${ }^{1}$ Federal Center of Technological Education of Rio de Janeiro (CEFET/RJ) - Brazil \\ ${ }^{2}$ Fluminense Federal University (IC/UFF) - Brazil
}

\begin{abstract}
Blended Learning (BL) environments are defined as tools that aim at aiding blended learning practices since they use new technologies to learners from constraints of time and place. A research target of this area is the use of new modeling techniques for this type of environment, taking into account not only aspects of data such as accounts, school infrastructures, but also educational profiles of the course and educational agents involved. In this paper we developed a modeling technique for $\mathrm{BL}$ targeting blended learning applications. Our modeling technique takes into account pedagogical observations and needs identified by actors (students, professors, and the staff involved in the development of the learning environment) to prepare BL environments. Our approach was evaluated using a distance-learning environment in a pilot class of Software for Tourism Course. The class aims at teaching software for professionals in this area. The implementation of pilot class allowed developers to have an initial contact with a productive and dynamic learning environment. Furthermore, it was possible to generate a real application based on the proposed approach.
\end{abstract}

Index Terms-Data Model, Blended Learning, IT.

\section{INTRODUCTION}

Blended Learning (BL) can be defined as ways to effectively combine different modes of delivery, teaching, and temporal characteristics in education [1]. It is a new learning and teaching mode that is increasingly applied in industry and academy domains in Brazil. It can be also considered as a modern version of correspondence education model widely used in the last century. It is considered as a quick way of teaching, training, and also as a means of self-development for the ones that use it. This method is part of an educational process, which is systematic, organized, and requires a two-way communication channel or the effective use of multimedia technologies for use these educational interactions. One of these new technologies, i.e. information technology (or simply IT), is extensively applied in blended learning practices, resulting in the presence of various new media development and communication in the learning process [2]. The use of BL in the academic environment started increasing from 2001, when it was enhanced by the explosive growth of the Internet and WWW. After that time, several educational institutes started using this methodology to aid students in their courses. In Brazil, distance learning, which allowed the usage BL was formalized in a 2005 (Decree number 5.622, 19th December 2005) presidential decree that states: "This decree characterizes distance education as educational modality, organized according to the methodology, management and peculiar evaluation" [3].

Although IT has added a different perspective for BL, defining how the computational environment is configured and modeled for supporting the learning process is still an open challenge. There are several existing pedagogical models that can be appropriate in this new area. This way, in BL we cannot ignore all the pedagogical models developed for education over the last centuries [4-8] even if they are not directly designed for BL. All of them can provide subsidies to educators to discover something about the methods and media used in order to make distance education possible. In this way, it is not the goal of this paper to propose new pedagogical models. Instead, in this paper we propose and describe a process for modeling the construction and development of class and courses based on BL using existing pedagogical models.

The goal is to develop a reference model for process of class construction in BL courses. Our model is designed in layers, where these layers address pedagogical aspects, content (i.e. course data itself) and finally an environmental organization layer. Part of the design of our model was inspired on data modeling techniques from Databases. Our reference model was applied in a pilot project, as a case study, which was the construction of a class of software for Tourism Course at the Federal Center of Technological Education of Rio de Janeiro (CEFET/RJ). A motivation to apply this model in this course was due to the fact that IT is part of the training needs for professionals in this area and there is a large demand of IT skills for the professionals during important events that will be held in Brazil such 2016 Summer Olympics and the 2014 FIFA World Cup.

Besides this introduction, the paper is divided into seven sections. Section II presents related work. Section III presents an overview of BL. Section IV presents an overview of the tourism course, which was the subject of the case study. Section V discusses general aspects of the data model. Section VI discusses our reference model. Section VII presents methodological discussion of the application of the model in the class of software for tourism course. Section VIII presents the results and finally, section IX concludes the paper.

\section{RELATED WORK}

There are many approaches related to blended learning in the literature [2,9-16]. Some of them focus on associating technological aspects with socio-psychological perspective of the students to create e-learning Web based modules $[9,10]$, whereas others focus on the behavior and attitudes of teacher or facilitators [11]. Recent works also 
focus on the collaborative learning in applications that can be used for BL $[2,12,13]$, while others focus on how tools can aid student learning process [14,15]. Finally, other initiatives focus on modeling applications for a particular class [16]. Following we present some of these approaches with more details.

The approach proposed by Derntl and MotschnigPitrick [9] is strictly related to the one proposed in this article. Derntl and Motschnig-Pitrick propose Bless, which is a layered framework to develop e-learning systems based on psychological perspective. Bless is based on the effective use of a Person-centered approach for a deep and persistent learning process. Bless also use an UML-based approach for modeling the learning process. However, in our paper we used UML as a representation model that follows a data modeling techniques from Databases. Bless is blended towards a network flavor, i.e., it is inspired in OSI layers. The have evaluated their framework on a Web engineering course and demonstrated that the proposed framework aided value to the work of educators.

Chrysafiadi and Virvou [10] present an interesting review of literature for blended learning. Besides present the most prominent approaches, they present a guide for making decisions about the techniques that should be adopted when designing e-learning systems and models. Motschnig-Pitrick and Derntl [11] discuss about their experience in blended learning in the university of Vienna, Austria. In their paper they show that when the students perceives that the teacher or tutor has person-centered attitudes, students have a better engagements to the classes, stating a self-motivated learning.

Andreas et al. [12] study the applicability of Second Life as a platform for collaborative learning tools. The authors implemented the educational environment considering avatars and learning objects in the Second Life environment. They applied this approach in a real class and showed that the usage of Second Life-based environments enhances the collaboration and learning space awareness. However, their paper does not take into account the socio-psychological perspective when developing learning tools. Isotani et al. [13] propose an intelligent authoring tool named CHOCOLATO that is based in the use of ontologies to model the knowledge involved in different pedagogies and practices related to the collaboration process. CHOCOLATO helps novice teachers in creating collaborative learning scenarios in their real classes. This paper also present a study in a Brazilian public school with 218 students and the authors showed that CHOCOLATO improved the overall performance throughout the year.

Juhary [14] presents a study with 10 young academics in Malaysia to elicitate their needs in order to develop a tool for teaching and learning. This study was performed in the National Defence University in Malaysia and presents several requirements that were already presented in our article. Similarly, Chen and Teng [15], presents a tool called Meeting-Flow Collaboration System (MFS) that aims at designing and helping collaborative teamwork in software engineering processes and system development. This system creates a collaborative and virtual environment for helping software engineers in their tasks related to the project. It was evaluated in a software engineering class and proved to be useful for improving the learning process in the software development lifecycle. Gálvez et al. [16] also present an experience of using blended e-learning in a course of object oriented programming; they used a problem-solving system for object oriented programming that helps students to practice the concepts and to understand their mistakes. They also used test systems that helped teachers to understand if the problem-solving system helps (or not) students while learning about object oriented programming. However, both approaches are preliminary studies and do not present any model that can be compared to the one proposed in our paper from the sociopsychological perspective.

\section{BACKGROUND ON DISTANCE LEARNING AND BLENDED LEARNING}

There is no consensual definition about the Distance Learning (DL) concept. Actually, there is a diversity of different definitions. For some authors [17-19], DL is associated to a physical and temporal separation between the student and teacher and as teaching process is performed in this space-time dimension. Other definition [20] considers not only the space-time dimension, but also the technologies used to manage this dimension, the modeling of the course and instructional techniques performed.

The use of the Internet and its variations (intranet and extranet) as ways of transmitting knowledge is a powerful ally in the implementation of the concepts of DL, because, through this technology, it is possible to promote the space-time dimension along with all kinds of resources for applying methods of teaching and learning of DL, such as access to texts, films, databases and discussion forums, as well as the presentation of interactive exercises, among other features [3]. The internet has become a way to exchange knowledge and information in a collective manner, without pre-definitions, different from a live class in which the student must be present at a specific time and more resources to exchange information between students themselves and between students and professors [21].

Despite these features, there are views of the DL that aim at increasing the diversity of learning, but not necessarily as a full replacement of the traditional class attendance in a classroom. This brings rooms for Blended Learning (BL), which mixture different ways of teaching, including both presential and distance learning. This way, DL should not be seen as unique teaching mechanism and should include mechanisms such as mentoring that meet the needs not covered by DL technologies in long-term courses [22,23].

DL can be divided in two modes according to Prinsloo, Slade and Galpin [24]: virtual mode and semi-presence mode. In virtual mode, all access to the content is remotely granted via Internet. There is the role of the tutor, to whom students report doubts in person or virtually. In person, interaction is commonly used to perform evaluations. In the semi-presence mode, there are educational stations where students go to study and to meet tutors. In this mode there is also the role of the online tutor, but the stations there is a present tutor with whom students can ask questions and participate in the activities requested in specific laboratories [22,23].

It is well known in Brazil that, in the case of implementing one or more Distance Learning (DL) class in an undergraduate course it cannot exceed $20 \%$ of the total amount of class of the course [3]. 
PAPER

TOWARDS A UML-BASED REFERENCE MODEL FOR BLENDED LEARNING

\section{CASE STUdy: The TOURISM COURSE}

The Tourism Course (TC) that was chosen as the case study in this paper is offered at CEFET/RJ. It provides a comprehensive curriculum for Tourism students. TC is based on the importance of promoting concepts and techniques related to the world of tourism and entertainment as well as to understand the relationships that are part of the tourism phenomenon, emphasizing the humanistic education of the student.

The TC was structured based in the Brazilian law number 9.394 of December 20th 1996 that defines guidelines and bases for national education (LDBEN) [3]. The TC curriculum consists of 20 classes in total. This course has a workload of 1,152 hours and lasts for 6 semesters. It offers classes include the main sectors that structure the Tourist System (Agency, Lodging, Transportation, Entertainment, Events) and qualifies students for medium and long-term job positions according the specific demands of tourism market sector of Rio de Janeiro. None of these classes is currently provided using BL environments. In special, one of the classes of the course is named "software for tourism". Currently, there is a lack of software professors to teach this class. Thus, the decision to offer this class in BL follows the aforementioned reasons and justifies our choice for this case study.

\section{Data Modeling Process BACKGROUND}

Almost all areas of knowledge, such as arts, social sciences, and software, make extensive use of models for representing relevant aspects of their environment. In an IT environment, these models can be used to explicitly represent characteristics of the real world that can be translated into methods and data that describe the operation and behavior of software components. Data modeling process creates elements (i.e. models) that ease the comprehension and design of an information system.

The data modeling process consists of three phases: Conceptual, Logical and Physical Modeling. The first one is used as a high-level representation and mainly considers perspective of users as creators. Some authors believe that perspective, to be effective, dispenses a pre-phase, called requirements analysis on which the key concepts associated with the problem domain are obtained. This information is used to design data models in the following phases. The second phase introduce some logical details that can be used to support the implementation, whereas the third phase works with the physical aspects of the data that goes into the model, as they are physically stored in a database, for example.

The objective of this modeling process is to analyze the environment in a data-centric perspective, with emphasis on modeling: (i) entities and relationships between them, (ii) logical data groups; and (iii) the life cycle of entities.

When it comes to notation, the conceptual model is a graphical representation that presents the components and concepts of the system that can be represented as entities and relationships between them. The logical model expands the concepts of the conceptual model, providing information in the form of tables, files, and also how they can be accessed, for example through mechanisms of primary keys, commonly used in database. Finally, the physical model includes the analysis of the characteristics and resources required for storage and manipulation of data structures identified, contemplating their storage structures, addressing, access and physical allocation.

Among the elements identified and generated through the phases, we can cite: (i) tangible elements: elements that have concrete existence, which take place in the problem domain; (ii) functions: identification of objects through their performed function (such as role, assignment, and classification); (iii) events: identification of actions that are related to objects identified in the domain of problems that can be either simple, such as insertions and changes; or complex, such as identification of relationships between them; (iv) Interactions: resulting associations between objects in terms of a process performed, in which each participating object interaction preserves its characteristics, not being impacted by the materialization of the interaction and $(v)$ specifications: elements that define characteristics of other objects.

\section{The Proposed REFERENCE MOdEL FOR BLENDED LEARNING}

Our proposed reference data model for BL applications is composed of three layers. The first layer defines educational and pedagogical standards, the second layer defines the aspects of the course content and the third layer defines the application environment where the course is instantiated.

It is worth to mention that our reference model is neither a methodology to build a new BL tool, nor a methodology to develop a new type of application. Instead, our reference model is conceived as an element that enables the construction of class development within a BL environment. To this extend, at the pedagogical perspective, it is not intended to establish a new approach for teaching, but benefit from existing models applied in the context of BL [26].

The first layer, named as pedagogical layer, is a layer that contains texts, documentation in narrative form, and elements of requirements analysis and conceptual model. The goal is to elicitate aspects related to the BL courses, considering pedagogical requirements identified by the professors. This layer establishes the problem domain, the people involved (students, professors), the object of the course, the motivation for using $\mathrm{BL}$, the learning methodology to be used and its supporting elements. As aforementioned, it is a narrative specification, whose information is derived from questionnaires and group interviews used to obtain data from the main actors (professors, students, academic managers, program coordinators, and staff). It is important to identify, using any of these methods, the following information: (i) Which are the goals to be achieved by the course; (ii) Who are the users and components of this course; (iii) What are the goals of providing the course (complementary goals); (iv) How well are pedagogical components organized; (v) How well are the contents of the course presented; (vi) What are the tools for teaching to be used (if identified). The output of this layer composes the information that aids the assembly of the elements of the content layer.

In the content layer, we use a visual model, based on the Unified Modeling Language (UML) [27] that is commonly used in software development. The purpose of this layer is to present the two main relationships mapped from the pedagogical layer: between the main actors and between the organization and pedagogical content itself. In the first part of the content layer, we deal with the relationships between main actors. It has the objective to 
present a hierarchy of access to a specific content, representing the organization's vision of access, to specify the main functions of each BL user and aids in identifying security aspects.

In the pedagogical and content relationships, the emphasis is to show the content tree of the course, its pedagogical structure, prerequisites and relationships with support tools (forums, chats etc.). It is important that this part of the model is able to show the type of content, so their view form, their way of update, relationships with other content, relationships with supporting tools and pedagogical vision of how that content should be covered.

In the environment layer, we describe the place in which all the physical elements specified in the content layer are going to be used. This layer not only defines IT platforms, but also all physical definition that might be required for the operation of educational activities defined in the first and second layer. This means that beyond the technical definitions, such as BL software applications, machines and operating systems, sets up any physical instrument necessary for the learning activities. To achieve this goal, we should include a description of elements such as classroom to support local access to computers that are not platform for installation of $\mathrm{BL}$ environment, other supporting tools, such as data projector, and whiteboards.

\section{APPLyING THE MODEL IN A TOURISM COURSE}

To demonstrate the effective use of the reference model proposed in this paper, we present the implementation of the class of "Software for Tourism" in a BL environment for TC course.

\section{A. Pedagogical Layer}

The construction of the pedagogical layer for the class of Software for Tourism of TC began with eliciting the learning needs. For this, we initially identified the main actors involved, including staff, target students, professors, coordinator of the TC, and coordinator of the research project. Once identified, each group was classified according to their importance in the teaching process. Professors received the highest value, followed by the coordinator of the TC, students, project coordinator of the research project, and finally staff. This ranking indicates a greater degree of pedagogical responsibility in relationship with the course, and the higher the value the greater the responsibility to define the pedagogical and didactic.

Following, we applied the methodology for obtaining information about the course. The requirements were gathered using interviews with two professors of the tourism course, to address perspectives and pedagogical advantages of the implementation of BL. We also interviewed some students, in order to obtain the students' feedback regarding this new approach and which requirements that would be relevant from their perspective. At last, we have conducted a final meeting with group of those surveyed students to consolidate the prospects of learning with this new technology, focusing on their opinions.

This information was then consolidated and evaluated with the TC coordinator, the coordinator of the project and the staff. In the meeting with the two professors, we presented the benefits of BL technology and its features. This meeting aimed at defining what would be the best strategy for building a BL environment for teaching Software for Tourism from the point of view of those who would administrate the class. At this meeting, it was possible to obtain the professors that could be addressed to the class of "software for tourism", and other items such as: strengthening the approach of a course containing practical information, enhancing the "how to", the description of the most used software in tourism area. One result of this meeting was a list of possible applications of being taught by BL and should be related to the needs of a professional tour, i.e., market vision. Another result achieved was that the development of the class in a BL environment, which was an entirely new experience for the TC and was started very carefully, on a trial basis.

Following the script previously drafted, the staff conducted a survey with students of the course, following the guidance of the TC coordinator, and checked what needs would be met immediately on learning of this class. It was provided a questionnaire for 32 students from several different stages of the tourism course. The purpose of this questionnaire was to obtain students' items of class that would be relevant to their academic life, thus identifying the expected didactic perspective and identifying some previous experience of using BL. In this questionnaire, it was inserted a set of six applications, nominated by professors at the previous meeting, and within these options would be chosen the 3 most voted, that would be those that would be implemented immediately. Table I presents the results obtained in the questionnaires.

It is important to emphasize that this questionnaire was also used to obtain the expectation didactic-pedagogic from the students. This is also motivated by the fact that the novelty of the use of BL. One result of the survey was that students chose learning more conventional IT tools such as MS-Excel ${ }^{\mathrm{TM}}$, MS-Word ${ }^{\mathrm{TM}}$ and MS-PowerPoint ${ }^{\mathrm{TM}}$, also known as MS-Office package ${ }^{\mathrm{TM}}$, instead of database software, specific software for tourism or electronic mail software. It was observed in offline conversation after applying the questionnaire, the reason students choose this package was due to the fact that this tool is so dominant in the market for tourism, is to build spreadsheets accounting, scheduling travel, construction documents or memoranda and presentations to build. The choice of software is not specific for tourism, since there is no standard software in the market, which would make the student, who is learning particular software, a specialist in a non-standard application.

Another important item that was obtained in this layer was the preference of student for lectures and teaching that added value to interactivity, i.e., there was a choice by exposing content with books, coupled with a need to have dynamism in the learning process. This is important information, since the BL contains both facilities desired.

After this questionnaire, there was another round of data collection, in which interviews were conducted with 15 students, chosen from the group of 32 who answered the questionnaire in order to identify how lessons should be submitted in the BL environment and how students could choose the format of classes, in videos, slides or handouts. 
TABLE I.

RESULTS OBTAINED IN THE QUESTIONNAIRE

\begin{tabular}{|l|c|}
\hline Application Options & \% of students \\
\hline Excel & $77 \%$ \\
\hline Word & $58 \%$ \\
\hline PowerPoint & $58 \%$ \\
\hline Access & $15 \%$ \\
\hline $\begin{array}{l}\text { Tourism Management } \\
\text { Software }\end{array}$ & $15 \%$ \\
\hline Outlook & $9 \%$ \\
\hline Do you know BL? & $23 \%$ yes, $77 \%$ no \\
\hline $\begin{array}{l}\text { What is the best } \\
\text { didactic form for you? }\end{array}$ & $\begin{array}{c}\text { 25\% expositive classes, } 20 \% \text { debates, } \\
\text { know }\end{array}$ \\
\hline $\begin{array}{l}\text { What is your stage in } \\
\text { the course? }\end{array}$ & $90 \%$ between fourth and sixth semester \\
\hline $\begin{array}{l}\text { Have you ever learned } \\
\text { from BL? }\end{array}$ & \begin{tabular}{l}
$13 \%$ yes, $87 \%$ no \\
\hline
\end{tabular}
\end{tabular}

As the result of the interviews, it was observed that $60 \%$ of these students found it easier that classes were presented as handouts and $40 \%$ preferred video lessons. Students also indicated a preference for the inclusion of an environment such as a forum or chat.

The summarization of this information helped us to define the course to encompass the teaching of the three top rated applications, MS-Excel ${ }^{\mathrm{TM}}$, MS-Word ${ }^{\mathrm{TM}}$ and MSPowerPoint ${ }^{\mathrm{TM}}$. It was also possible to identify the preferred class model, which was focused on the use of textbooks that are easily accessible. The staff and coordinator of TC produced the handouts using Portable Document Format (PDF).

Another result focused on pedagogical content for that layer, i.e., the way in which the course should be presented. The class was divided into three modules, one for each selected tool. Each module contains at least two and at most four topics. Also, each module can be accessed independently, that is, there would be a prerequisite among the modules. The topics within the module should be successively attended, that is, a topic can only be considered open when the previous access was completed.

Students connect to the BL environment using passwords and they are granted access to the pilot course. Students' access in the course can be queried by professors and administrators, which allowed them to check students' attendance. Finally, another tool defined for the BL that was also based on the interviews comprehends the inclusion of a forum to allow students to solve their doubts.

\section{B. Content Layer}

In this layer, we use a data-modeling tool to present the relationship between the actors involved and the content identified in the pedagogical layer. When assembling the visions of these relationships, we built the model with flexibility, focusing on objects that compose the design. The identified objects are those that have been obtained from the analysis of the pedagogical layer. The content layer was modeled through class diagrams in UML; which is a modeling language that facilitates the presentation of these types of relationships, helping in understanding their association and hierarchy. The model for the case study is shown in Figure 1.

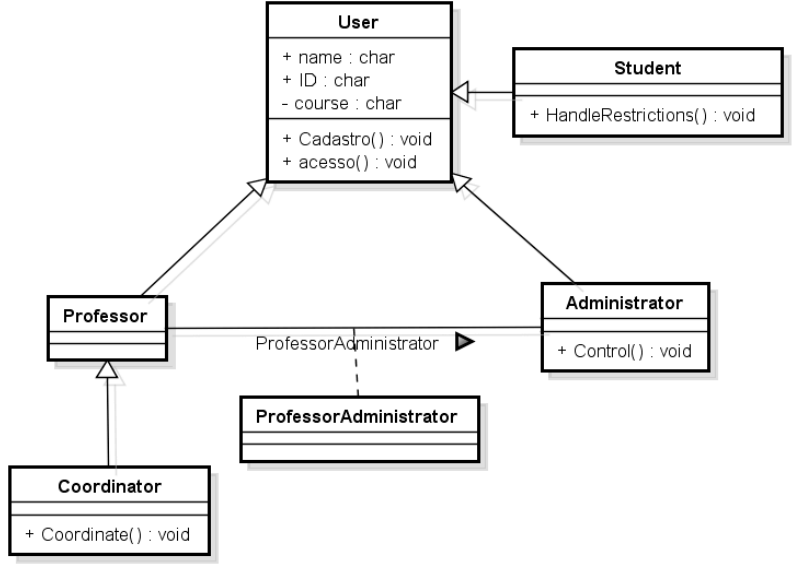

Figure 1. Relationship between classes

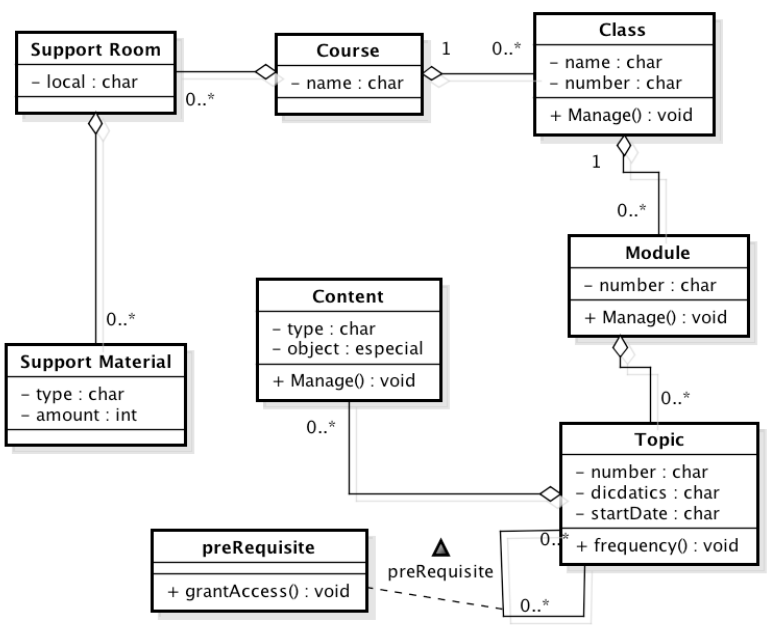

Figure 2. Pedagogical relationships

In this model, we identified the key actors in the pedagogical relationship, according to the necessary functions for BL, such as manipulating the non-DL and DL environments, which would be: students, professors, administrators and coordinators. Students are those who would be entitled to registration functions (with insertion, modification, query and deletion) and the access function containing restrictions on handling the pedagogical environment. Nevertheless, the professor has no restrictions and can act as administrator, which allows a super user to control the environment. A professor is the one that actually runs the course. This administrator role is associated with DL environment, that is, those who work directly in the environment, the entire building security mechanism and restriction of the tool, since the coordinator's role would be beyond the DL tool. The pedagogical relations can be seen in Figure 2.

The identified objects, and their relationships, for this case study were "course" (with their identifying attributes). It corresponds to four main components: the "class" (in our study, only one was implemented) and the "room" (or ambient). The class has modules (minimum 2 and maximum 4), which in turn are formed by topics. The topics have a self-relationship based on conditions prerequisites, so that they only grant access to a topic when it prerequisites are fully complied with. The mechanism for indicating the end of all topics is the end of the last topic, which is a test for the student. This support environment is formed by all material that might be 
required. In the present study, we did not identify the need for tutors.

\section{Environment Layer}

The environment layer is the place in which the components are described physically to allow the operation of logic elements identified in the content layer. Besides containing these components (BL software, network, machines), in this layer we also describe the procedures for the development of the general BL environment. Even when we identify the need for physical components that do not pertain directly to the $\mathrm{BL}$, from the point of view of IT technology, they are also described.

This layer can be described using a narrative, visual or using a specific tool. In this layer, we define all components and installation procedures for setting up the BL environment and supportive environment for the course. The first step to be described in this layer is related to the choice of BL tool to define thereafter where all necessary components for its operation (operating system, engine, etc.) are associated.

In the case study proposed in this paper, we used Moodle as a platform for the DL scope of BL, since it is a learning management system (LMS) most used nowadays, and it is open source [28,29]. All data in the Moodle is stored in MySQL databases [30].

The Moodle system began to be conceived in the early 90s at Curtin University of Technology in Australia and responsible for administering the LMS used by the University at that time. It is not only used by universities, but in high schools, primary schools, organizations, private companies, and by independent professors. The development of Moodle environment was guided by a theory of philosophy of learning - social constructivist $[31,32]$.

Moodle allows you to create three formats of courses: social, weekly and modular. The social course is based on social interaction capabilities between participants and non-structured content. The last two courses are structured and modular and can be weekly. These courses are focused on content availability and definition of activities [33]. In the weekly structure we report the period in which the course are taught and the system divides the reporting period, automatically, in weeks. In the modular structure, we inform the amount of modules. It also has all the main features of a virtual learning environment [22]. Moodle provides communication tools, assessment, management and organization. They are accessed by the tutor separately in two types of entries in the course page. On one side, add the material (contents) and other activities, and activities can be added to communication tools, assessment tools and other additional content. The administration tools used by the tutor allow for controlling participants; to perform backups and restore of courses, access to log files, logs the last minute, file management courses; release notes.

The Moodle platform used in the case study of this paper was installed in an operational environment MSWindows Server 2003 SP2 ${ }^{\text {TM }}$. This software is a network operating system that runs as a network server for medium and large size and runs on Intel, AMD or similar. It was released in 2003 and is still available in the market, although there are already new versions released by Microsoft ${ }^{\mathrm{TM}}$. MS-Windows Server is a robust, multitasking system, supports processing with 32 or 64 bits, which makes it very efficient in solving the tasks. Security environment has a well-established solution, based on the architecture called Active Directory. Moreover, it also has an easy and intuitive visual interface. This system supports all auxiliary elements for the operation of Moodle: the MySQL database, the Apache Tomcat Web server, which is needed to allow for Web access of subjects and courses administered by Moodle. This allows the network configuration in order to make possible access Moodle remotely, within the safety aspects expected by the machines of the institution's network.

We installed the entire platform in a Dell OptiPlex, 780, with 4GB RAM, 320GB HD with two NICs Ethernet $10 / 100 / 1000$ bps. Domain space has been created within this machine, allowing it to be accessed by anywhere in the institutional network. In parallel, we installed a Web page server, the Apache Tomcat, Windows version, and MySQL database, according to the guidelines of the manual installation of Moodle.

Once completed all installation procedures we performed platform settings to adjust the access to the course, including: adjustment for inclusion of course, setting student access, setting the permissions of students, environment configuration forum adjustments and configuration via Web server to allow external access, such as ICMP settings and access to port 8080 , so the Moodle page could be accesses by all machines in the network.

After setting up the environment, and the forms of access, we proceeded to test network access. Tests were performed by creating users with varying degrees of security, including providing access to the forum area. Once we set the BL operating environment part we started customizing the entire environment according to the educational support that was requested.

\section{RESULTS ACHIEVED}

The implementation of the course and lessons on the environment was assembled from the mapping of the proposed model and started with the settings of the course. Such configurations were performed using the administrator privileges. We started by creating the course and the classes, considering the full name in case: "Software for Tourism", containing an abbreviation, which appears as a caption on the menu of "Meus Cursos", as can be seen in Figure 3.

After the course has been created with its characteristics, we performed insertion classes, and each class was associated with a tool of MS-Office ${ }^{\mathrm{TM}}$ chosen in pedagogical layer. For each of these classes were inserted associated modules, and for the MS-Word ${ }^{\mathrm{TM}}$ class were inserted 4 modules (three textbooks and a test - i.e. Moodle Lesson), for the class of MS Excel ${ }^{\mathrm{TM}}$ we inserted 3 modules and for MS-PowerPoint ${ }^{\mathrm{TM}}$ class we inserted 2 modules, remembering that the last module is always the test and have to be completed so that you can access the next. It is worth noticing that the most important factor for each module was the content, and it was represented in PDF format. This can be seen in Figure 4. Once the class has been created, the administrator can then associate with the same content, which in this case study was the inclusion of PDF handouts. An example of such inclusion can be seen in Figure 5. 


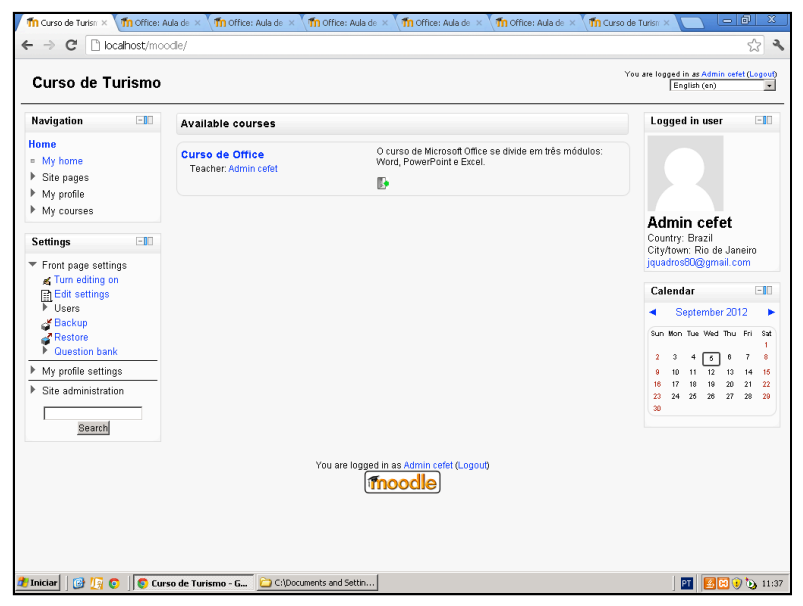

Figure 3. Inserting a course and class in the environment

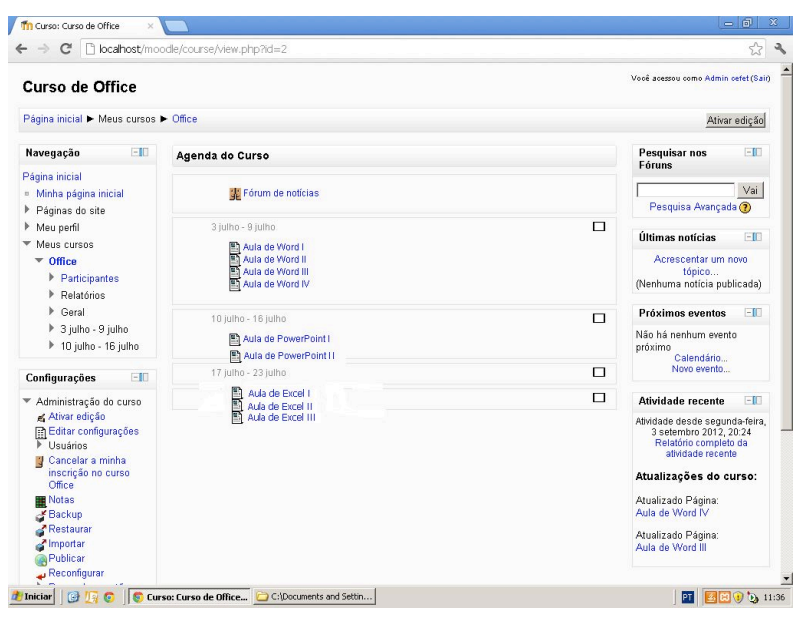

Figure 4. Inserting modules in the environment

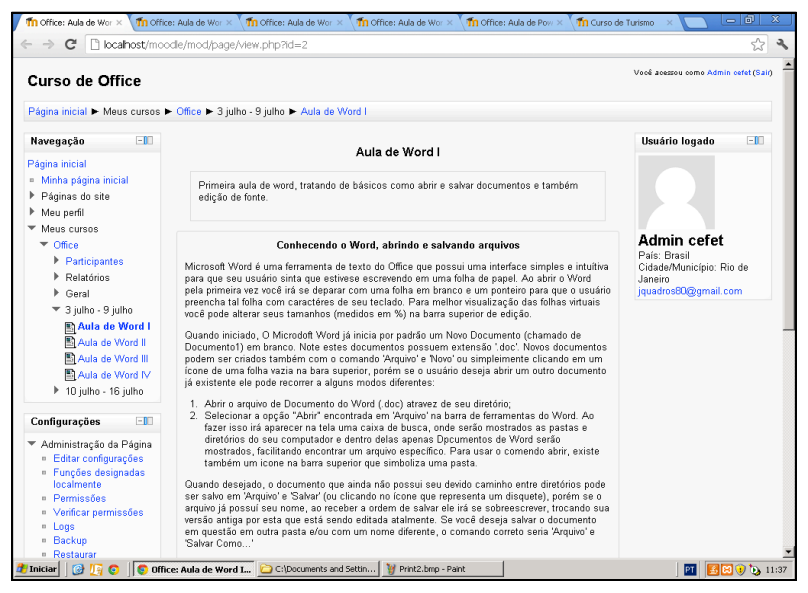

Figure 5. Inserting content in the environment

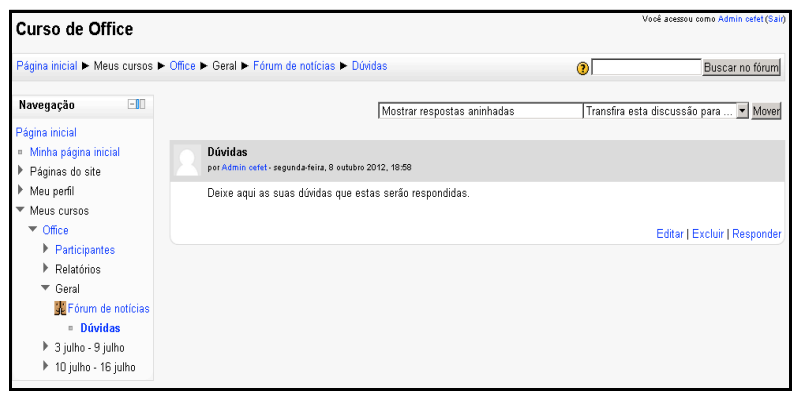

Figure 6. Forum of the environment
After these steps were performed, the environment is ready for students to use. In order to access the Moodle, students have to sign a form and send it to the staff. This step was useful to prevent access from undesired users. The teacher who enrolls students will also select the option to assign roles, associating them as "student" of this specific course. This description may be by name, social security number (i.e. CPF in Brazil) or e-mail. After these procedures, the student will be able to access classes.

In addition to the classroom environment, we configured, as defined in the pedagogic layer, a forum, as seen in Figure 6.

\section{CONCLUSIONS AND FINAL REMARKS}

The proposed model enabled a systematic way to prepare the course containing the class of Software for Tourism in a BL environment. Based on the results produced by the pedagogical layer, content layer and environment layer, the task of building the BL class for TC was very productive. This way, the proposed model eases the work of the staff and professors, since the products developed were target directly in agreement with students' desires, leading in very little demands for changes and adjustments. The tourism course was built to address the software considered relevant by the interviewees, focusing on the standard software of the tourism market, and has been formatted as a set of handouts in PDF, containing exercises and tests. All of these items were obtained from the applied modeling process.

Our option to adopt a simple course structure, with modules and classes, was because the vast majority of students showed that they had no prior knowledge or training in the BL domain. Yet the application of this learning method, constructed according to the pedagogical criteria, increased the productivity of the students in this course. Such fact will be investigated in a future work.

\section{REFERENCES}

[1] M. Kaur, 2013, "Blended Learning - Its Challenges and Future", Procedia - Social and Behavioral Sciences, v. 93 (Oct.), p. 612617.

[2] C. Fang Fang and L. Chien Sing, 2009, "Collaborative learning using service-oriented architecture: A framework design", Knowledge-Based Systems, v. 22, n. 4 (May.), p. 271-274.

[3] ABED, 2014, "Analytic report of distance learning in Brazil", http://www.abed.org.br/censoead/censo2012_ingles.pdf.

[4] S. Papert, 1993, "The children's machine: rethinking school in the age of the computer". New York, BasicBooks.

[5] P. Lévy, 1990, "Les technologies de l'intelligence: l'avenir de la pensée à l'ère informatique". Paris, Editions La Découverte.

[6] J. Piaget, 1970, "Genetic epistemology". New York, Columbia University Press.

[7] H. Daniels, 2005, "An introduction to Vygotsky". London; New York, Routledge.

[8] P. Freire and P. Freire, 1976, "Education, the practice of freedom". London, Writers and Readers Publishing Cooperative.

[9] M. Derntl and R. Motschnig-Pitrik, 2005, "The role of structure, patterns, and people in blended learning", The Internet and Higher Education, v. 8, n. 2 (Jan.), p. 111-130. http://dx.doi.org/10.1016/ j.iheduc. 2005.03 .002

[10] K. Chrysafiadi and M. Virvou, 2013, "Student modeling approaches: A literature review for the last decade", Expert Systems with Applications, v. 40, n. 11 (Sep.), p. 4715-4729. http://dx.doi.org/10.1016/j.eswa.2013.02.007

[11] R. Motschnig-Pitrik and B. Standl, 2013, "Person-centered technology enhanced learning: Dimensions of added value", Computers in Human Behavior, v. 29, n. 2 (Mar.), p. 401-409. 
http://dx.doi.org/10.1016/j.chb.2012.04.013

[12] K. Andreas, T. Tsiatsos, T. Terzidou, and A. Pomportsis, 2010, "Fostering collaborative learning in Second Life: Metaphors and affordances", Computers \& Education, v. 55, n. 2 (Sep.), p. 603615. http://dx.doi.org/10.1016/j.compedu.2010.02.021

[13] S. Isotani, R. Mizoguchi, S. Isotani, O.M. Capeli, N. Isotani, A.R.P.L. de Albuquerque, I.I. Bittencourt, and P. Jaques, 2013, A "Semantic Web-based authoring tool to facilitate the planning of collaborative learning scenarios compliant with learning theories", Computers \& Education, v. 63 (Apr.), p. 267-284. http://dx.doi.org/10.1016/j.compedu.2012.12.009

[14] J. Juhary, 2012, "Making Sense of e-Learning and Simulations: The Misunderstood Perceptions", Procedia - Social and Behavioral Sciences, v. 67 (Dec.), p. 229-237.

[15] C.-Y. Chen and K.-C. Teng, 2011, "The design and development of a computerized tool support for conducting senior projects in software engineering education", Computers \& Education, v. 56, n. 3 (Apr.), p. 802-817. http://dx.doi.org/10.1016/j.compedu. 2010.10 .022

[16] J. Gálvez, E. Guzmán, and R. Conejo, 2009, "A blended Elearning experience in a course of object oriented programming fundamentals", Knowledge-Based Systems, v. 22, n. 4 (May.), p. 279-286.

[17] D. Elkins and D. Pinder, 2012, "E-learning uncovered: articulate storyline". Jacksonville, Fla., Alcorn Ward \& Partners.

[18] R.C. Clark and R.E. Mayer, 2003, "E-Learning and the science of instruction: proven guidelines for consumers and designers of multimedia learning". San Francisco, CA, Jossey-Bass/Pfeiffer.

[19] D.R. Garrison, 2011, "E-learning in the 21st century a framework for research and practice". New York, Routledge.

[20] M.G. Moore and G. Kearsley, 2011, "Distance education: a systems view of online learning". Belmont, CA, Wadsworth Cengage Learning.

[21] L. Razmerita and A. Brun, 2011, "Collaborative Learning in Heterogeneous Classes - Towards a Group Formation Methodology", In: CSEDU (2)'11, p. 189-194

[22] T. Martindale and M. Dowdy, 2010, "Personal Learning Environments".

[23] S. Leone, 2013, "Characterisation of a personal learning environment as a lifelong learning tool". New York, Springer. http://dx.doi.org/10.1007/978-1-4614-6274-3

[24] P. Prinsloo, S. Slade, and F. Galpin, 2012, "Learning analytics: challenges, paradoxes and opportunities for mega open distance learning institutions", In: Proceedings of the 2nd International Conference on Learning Analytics and Knowledge, p. 130-133 http://dx.doi.org/10.1145/2330601.2330635

[25] J.V. Carlis and J.D. Maguire, 2001, "Mastering data modeling: a user-driven approach". Boston, Addison-Wesley.

[26] R.C.A. Fernandes and J.M. Neto, 2012, "Educational models in academic research on the teaching practices in science education in elementary school", Investigações em Ensino de Ciências, v. 17, n. 3, p. 641-662.

[27] M. Fowler, 2004, "UML distilled: a brief guide to the standard object modeling language". Boston, Addison-Wesley.

[28] Moodle, 2013, http://moodle.org/about/.

[29] M.C. Garbin, S.F. do Amaral, C.O.S. Mendes, E. Ogasawara, and J.M. de S. Rocha, 2012, "Adaptation of the Moodle for
Application in Distance Education Course at the State University of Campinas", Procedia - Social and Behavioral Sciences, v. 46, p. 2514-2518.

[30] MySQL, 1997, "MySQL 5.0 Reference Manual" URL: http://dev.mysql.com/doc/refman/5.0/en/innodb-index-types.html.

[31] L.S. Vygotskii and M. Cole, 1978, "Mind in society: the development of higher psychological processes". Cambridge, Harvard University Press.

[32] A. Gaspar and I.C. Monteiro, 2005, "Experimental activities of classroom demonstrations: an analysis according to Vygotsky" theory, IENCI, v. 10, n. 2

[33] M.B. O'Leary, M. Mortensen, and A.W. Woolley, 2011, Multiple Team Membership: "A Theoretical Model of its Effects on Productivity and Learning for Individuals and Teams", SSRN Scholarly Paper ID 1474336, Social Science Research Network. URL: http://papers.ssrn.com/abstract=1474336.

\section{AUTHORS}

J. R. Quadros is at Computer Science Department of Federal Center of Technological Education of Rio de Janeiro, Av. Maracanã, 229, Rio de Janeiro, RJ, 20271110 (e-mail: jquadros@cefet-rj.br). He is current coleading the research group of Computing in Education at CEFET/RJ.

D. de Oliveira is at Computing Institute of Fluminense Federal University, Rua Passo da Pátria 156, Niterói, RJ, 24210-240 (e-mail: danielcmo@ic.uff.br). He has received the Doctor of Science degree from UFRJ in 2012. Dr. Oliveira's current research interests include distributed and parallel databases, data management aspects of scientific workflows. He has published over 50 refereed international journal articles and conference papers.

A. Queiroz is at Tourism Department of Federal Center of Technological Education of Rio de Janeiro, Av. Maracanã, 229, Rio de Janeiro, RJ, 20271-110 (e-mail: ambrozio@cefet-rj.br).

E. Ogasawara is at Computer Science Department of Federal Center of Technological Education of Rio de Janeiro, Av. Maracanã, 229, Rio de Janeiro, RJ, 20271110 (e-mail: eogasawara@cefet-rj.br). He is current leading the research group of Applied Computing at CEFET/RJ.

C. Schocair is at Computer Science Department of Federal Center of Technological Education of Rio de Janeiro, Av. Maracanã, 229, Rio de Janeiro, RJ, 20271110 (e-mail: schocair@cefet-rj.br). He is current coleading the research group of Computing in Education at CEFET/RJ.

This work was supported in part by CNPq and FAPERJ. It is an extended and modified version of a paper presented at the ICBL2013 International Conference on Interactive Computer aided Blended Learning, held 6 - 8 November 2013, in Florianópolis, Brasil. Submitted, January 5, 2014. Published as resubmitted by the authors on April 5, 2014. 